\title{
Significados de las fiebres del dengue, chikungunya y zika $e$ itinerarios terapéuticos en un municipio endémico de Colombia
}

\section{Meanings of dengue, chikungunya and zika and therapeutic itineraries in a Colombian endemic municipality}

\author{
Claudia Hormiga Sánchez ${ }^{a}$ \\ (D) https://orcid.org/0000-0002-8723-666X \\ E-mail: chormiga®unab.edu.co

\section{Claudia Cortes García} \\ (D) https://orcid.org/0000-0003-1939-7653 \\ E-mail: claudiam.cortesळurosario.edu.co \\ Yaneth Becerra Fajardob \\ (D) https://orcid.org/0000-0002-1617-5871 \\ E-mail: yaneth. becerraळurosario.edu.co \\ Johan Ariza Abril ${ }^{b}$ \\ (D) https://orcid.org/0000-0002-5520-8090 \\ E-mail: johan.ariza®urosario.edu.co

\section{Diego Garzón Forerob} \\ (D) https://orcid.org/0000-0002-0806-1356 \\ E-mail: diego.garzonœurosario.edu.co

\section{Laura Cadena Afanador} \\ (iD) https://orcid.org/0000-0001-9032-3599 \\ E-mail: Icadenaœunab.edu.co
}

aniversidad Autónoma de Bucaramanga. Facultad de Ciencias de la Salud. Programa de Medicina. Bucaramanga, Colombia.

bUniversidad del Rosario. Escuela de Ciencias Humanas. Programa de Antropología. Bogotá, DC, Colombia.

\section{Resumen}

Investigación cualitativa para dilucidar construcciones sociales sobre el dengue, chikungunya y zika en un municipio endémico de Colombia. Participaron 61 personas con experiencia subjetiva de enfermedad. Se emplearon entrevistas semiestructuradas y abiertas, diálogos informales y registro de notas de observación. El análisis se realizó siguiendo el método inductivo de la investigación social. Se evidencian dos maneras de entender el dengue: como una enfermedad "normal" o como una enfermedad grave que puede causar la muerte. El chikungunya y el zika son concebidas como enfermedades nuevas, de difícil reconocimiento, que caen en el olvido social ante la baja ocurrencia de casos. Se identifican dos itinerarios terapéuticos frente a las tres enfermedades, mediados por la gravedad de los síntomas y la percepción de la atención recibida por los servicios sanitarios. Las droguerías se configuran como un elemento clave de los itinerarios terapéuticos. Se concluye que la construcción social de estas enfermedades está atravesada por una tensión entre el reconocimiento y el olvido. Las políticas y acciones públicas tendientes a la prevención y el control de estos eventos tienen el reto de enfrentar el "olvido" que trae la cotidianidad, por tanto no deben limitarse a abordajes que ignoran las maneras en que las enfermedades son vividas y afrontadas.

Palabras clave: Dengue; Zika; Chikungunya; Antropología Médica; Narrativas Personales Como Asunto.

\section{Correspondencia}


Qualitative research to elucidate social constructions about dengue, chikungunya and zika in an endemic municipality of Colombia. Sixtyone people with subjective experience of disease participated. Semi-structured and open interviews, informal dialogues and observation notes record were used. The analysis was performed following the inductive method of social research. Two ways of understanding dengue are evident: as a "normal" disease or as a serious disease that can cause death. Chikungunya and zika are conceived as new diseases, of difficult recognition, that fall into social oblivion due to the low occurrence of cases. Two therapeutic itineraries for the three diseases are identified, mediated by the severity of the symptoms and the perception of the attention received by the health services. Drugstores are configured as a key element of therapeutic itineraries. It is concluded that the social construction of these diseases is crossed by a tension between recognition and forgetfulness. Public policies and actions aimed at the prevention and control of these events have the challenge of facing the "forgetfulness" that daily life brings, therefore they should not be limited to approaches that ignore the ways in which diseases are lived and faced.

Keywords: Dengue: Zika; Chikungunya; Medical Antropology; Personal Narratives as Topic.
El control de las enfermedades transmitidas por artrópodos, en particular por los mosquitos del género Aedes, continúa siendo una prioridad de salud pública no solo en Colombia sino en gran parte del continente americano y, en general, en todas las áreas tropicales y subtropicales del mundo (GuhaSapir; Schimmer, 2005; WHO, 2012).

Específicamente en Colombia existe gran presencia del mosquito Aedes (más del 90\% del territorio nacional situado por debajo de $\mathbf{2 . 2 0 0}$ ms.n.m.), que unida a la introducción de Aedes albopictus y la urbanización de la población por desplazamientos debido a problemas de violencia, entre otros, se han visto reflejadas en una transmisión de dengue intensa y creciente, con ciclos epidémicos cada 3 a 5 años, así como la reciente transmisión autóctona de chikungunya y fiebre por virus zika (Castrillón; Castaño; Urcuqui, 2005; Jaramillo-Tobón, 2015).

En las casi tres décadas anteriores (1990-2016), se registraron en el país 1.401.240 casos de dengue, con una progresiva tendencia ascendente más acentuada a partir de 2010 (Padilla et al., 2017). Al interior del país, Floridablanca, en Santander, es uno de los municipios con mayor número de casos de dengue y dengue grave notificados año a año (Castrillón; Castaño; Urcuqui, 2005; Padilla et al., 2017). En consonancia con el comportamiento del dengue, Floridablanca y Santander también han sido territorios con mayor notificación de casos de chikungunya y fiebre por zika en el ámbito nacional y cuentan con altas incidencias acumuladas por estos eventos.

Detrás de la presencia de los mosquitos que transmiten los virus responsables de estas tres enfermedades (y otras potenciales) existen factores sociales, culturales, políticos, económicos y ambientales a gran escala, que imponen un gran reto para lograr su control y, en consecuencia, la menor presencia de virus circulantes y de personas enfermas. Siguiendo directrices de agencias internacionales, en el país se han desarrollado diferentes campañas durante las últimas décadas enfocadas en controlar y prevenir la ocurrencia del dengue, así como elevar la conciencia sobre la 
enfermedad (Suárez et al., 2005, 2009). Para esto se han realizado intervenciones que buscan dar lugar a un cambio de comportamiento en las poblaciones con el fin de promover estilos de vida que mejoren la salud humana, empleando principalmente metodologías basadas en un enfoque conductual para la comprensión del comportamiento humano con el fin de arrojar alguna luz sobre las enfermedades transmitidas por vectores (Suárez et al., 2005).

Sin embargo, los aspectos culturales del dengue, lo que este significa en la cotidianidad de las personas, y en general, los determinantes sociales del dengue han sido poco estudiados afín al panorama mundial (Arauz et al., 2015; Guha-Sapir; Schimmer, 2005). Investigaciones desde la antropología médica han evidenciado en Colombia un desencuentro entre las realidades pensadas desde las agencias internacionales e instituciones oficiales en torno al dengue y las experiencias cotidianas de los actores sociales (Suárez; González; Viatela, 2004; Suárez et al., 2005).

Dada la reciente introducción de los otros dos virus transmitidos por mosquitos Aedes en el territorio colombiano, es importante avanzar en el estudio del comportamiento conjunto de estas enfermedades y dilucidar aspectos que influyen en su ocurrencia en los contextos locales. Este reporte hace parte de una investigación con abordaje mixto encaminada a comprender la distribución y transmisión del dengue y la fiebre por zika en el municipio de Floridablanca (Santander) a partir del comportamiento geoespacial y temporal de los casos notificados individualmente durante el periodo 2014-2015 y de los vínculos entre el dengue, el chikungunya y el zika con aspectos socioculturales de la población entre 2016 y 2018.

De manera específica, este reporte centra su interés en las construcciones simbólicas de las tres enfermedades a partir de la manera en que éstas son entendidas así como en las formas en que se establecen unos itinerarios terapéuticos frente a estas en la cotidianidad. Conceptualmente, los itinerarios terapéuticos son los caminos que definen las personas en busca de restablecer su condición de salud y expresan construcciones subjetivas individuales y colectivas del proceso de la enfermedad y formas de tratamiento, forjado bajo la influencia de diversos factores y contextos (Cabral et al. 2011).
Estos caminos incluyen múltiples alternativas que interactúan paralelamente y conforman respuestas hibridas (desde los cuidados caseros y prácticas religiosas hasta los dispositivos biomédicos predominantes), mostrando que el proceso saludenfermedad-atención responde a diferentes posibilidades interpretativas y lógicas de acción (Alves; Souza, 1999). En este enfoque, siguiendo a Menéndez (2003)y Abadía-Barrero y Oviedo-Manrique (2009), la noción de itinerarios terapéuticos es una herramienta teórica y metodológica que ofrece una aproximación para interpretar cómo las experiencias del enfermar y el atenderse se crean, redefinen, responden y reproducen las dinámicas de los entornos globales y locales. A partir de este conocimiento es posible propiciar un acercamiento entre los lenguajes del sistema sanitario y los organismos de control con el de la cotidianidad de las personas. Esta investigación fue aprobada por el Comité Institucional de Ética en Investigaciones de la Universidad Autónoma de Bucaramanga.

\section{Metodología}

A partir de un análisis geoespacial y temporal de casos notificados durante los años 2014 y 2015 se seleccionaron conglomerados poblacionales urbanos del municipio de Floridablanca que concentraban un alto número de casos de dengue y fiebre por zika. Todos los conglomerados correspondieron a sectores de estratos socioeconómicos 1 a 4 (bajo y medio), en donde se realizaron abordajes etnográficos en diciembre de 2016 o en enero de 2018.

Participaron 61 residentes ( 38 en 2016 y 27 en 2018) con experiencia subjetiva de enfermedad, quienes fueron contactados por intermedio de líderes comunitarios o por bola de nieve. Para la recolección de la información se emplearon entrevistas semiestructuradas y abiertas, diálogos informales y registro de notas de observación en diario de campo (voz y escritas). Con esta aproximación se tomó como eje principal la concepción valorativa de las personas y su percepción acerca de: primero, los significados sociales que adquiere el mosquito Aedes y las enfermedades y cómo se convive con estos; y, segundo, las maneras en que las personas responden socialmente a partir de sus 
conocimientos, percepciones y representaciones, configurando itinerarios terapéuticos en relación a su propia vivencia de la enfermedad.

Todas las entrevistas se realizaron en las viviendas o sitios de trabajo de los participantes (plazas de mercado, tiendas, misceláneas, montallantas o droguerías). Con previo consentimiento de los participantes, las entrevistas fueron grabadas en audio y posteriormente transcritas en archivos de texto.

Se recolectó información hasta lograr saturación de categorías teniendo como ejes de análisis la cotidianidad, los saberes locales y la pluralidad terapéutica. El análisis se realizó en dos momentos subsecuentes a los periodos de la recolección de datos, lo cual permitió que el trabajo de campo y análisis del 2018 estuviera direccionado por los hallazgos obtenidos en el 2016.

Para el análisis de la información se utilizó el método inductivo de la investigación social (Miles; Huberman, 200o) siguiendo las siguientes etapas: lectura abierta, codificación por ciclos (Saldaña, 2013), análisis estructural e interpretación crítica. Inicialmente, todo el equipo investigador realizó codificación de textos, y en reuniones de discusión se hizo la reducción de categorías e la interpretación crítica. La información correspondiente a las categorías se manejó en matrices cualitativas de análisis usando hojas de cálculo para su sistematización y para adelantar los análisis relacionales. Para garantizar la calidad de la información, el proceso de recolección y análisis fue sometido a la triangulación teórica por los investigadores.

\section{Resultados}

Las construcciones simbólicas de estas tres enfermedades están mediadas por los aprendizajes y las experiencias de las personas, de las cuales se deriva, por un lado, el conocimiento laico o popular que configura su identidad; y por otro, las maneras de afrontarlas en la cotidianidad. Estas dos aristas evidenciaron algunas de las relaciones existentes entre la población y el sistema sanitario del país. A continuación se presentan las categorías emergentes sobre la identidad de las enfermedades, la definición de un pluralismo médico en la resolución de estas, y en este marco, el establecimiento de unos itinerarios terapéuticos vinculados al afrontamiento de los síntomas y secuelas. Se incluyen testimonios de los participantes que dan soporte a los hallazgos presentados.

\section{Dengue, chikungunya y zika: construcciones desde las vivencias y aprendizajes en el reconocimiento de la enfermedad}

El dengue y el dengue grave (el hemorrágico) son entendidas como enfermedades separadas. El primero, reconocido por las personas como una enfermedad de ocurrencia "normal" o "tradicional", representa una experiencia frecuente de enfermedad, caracterizada por fiebre, malestar y dolor corporal, claramente diferenciada de una gripa o resfriado, porque a diferencia de estos, el dengue no incluía síntomas respiratorios (Tabla 1, cita 1); y, el segundo, con manifestaciones más fuertes como broto y sangrado, es asociado a la gravedad y a la posibilidad de morir (Tabla 1, cita 2).

El zika y el chikungunya son concebidas como enfermedades lejanas, benignas, nuevas y de difícil diferenciación entre ellas, especialmente en los participantes entrevistados en el 2018 (Tabla 1, cita 3 y 4). Se relacionan principalmente con malestar y dolores articulares residuales (Tabla 1, cita 5). En el caso particular del zika hay una remisión directa al embarazo como agravante de la enfermedad (Tabla 1, cita 6).

La mayoría de los participantes reconocen a un mosquito con características particulares cuya picadura transmite o causa todas estas enfermedades, aunque las descripciones sobre este son vagas, su nombre científico es escasamente mencionado, y se hace escasa alusión a virus involucrados (Tabla 1, cita 7 y 8). Los síntomas son los que le permiten a las personas aproximarse a cuál de estas específicas se padece. El broto, el sangrado y la baja de las plaquetas (referidas de manera indistinta con las defensas) son evidencias de que algo no está bien y diferencian el dengue "normal" del dengue "hemorrágico". El fuerte dolor articular durante y después del curso de la enfermedad es característico de la noción de las enfermedades nuevas, en especial del chikungunya. 
Estas nociones están relacionadas con las formas en que las personas acceden al conocimiento sobre estas tres enfermedades. En nuestro caso, al hablar de acceso al conocimiento se hicieron notorias tres grandes influencias por las cuales se genera un aprendizaje sobre estas y los modos de tratarlas: los medios masivos de comunicación (televisión, internet y radio), las campañas educativas de las secretarías de salud y el "voz a voz". Se percibe cómo la definición de las enfermedades tiene una presencia temporal ligada a los periodos de mayor presencia de casos en los que el "voz a voz", la presencia comunitaria de los servicios de salud y la información de los medios de comunicación son más acentuadas (Tabla 1, cita 8). Sin embargo, la capacidad para identificar las enfermedades "nuevas" y diferenciarlas del dengue se diluye al mermar su presencia en el territorio, siendo común la identificación de un síntoma principal, la fiebre, para expresar la ocurrencia de alguna de estas enfermedades, dando así lugar a un "olvido" temporal de las mismas (Tabla 1, cita 9).

\section{Tabla I - Citas sobre el reconocimiento del dengue, el chikungunya y el zika}

Texto
es que el dengue no da gripa. La gripa a veces da un escalofrío, da dolor de cabeza... [en el
dengue] lo que le digo es el dolor de abdomen y dolor de huesos, de todos los huesos que no es Fuente
capaz ni de mover. [Dan los síntomas y uno dice] "hay un malestar, una virosis". Cuando fue que hombre, 2016
llegué a la clínica y me dejaron allá y yo dije "no, qué virosis".

El dengue, para mi el dengue es el más grave... la niña cuando entró en crisis estaba mal, ella no abría los ojos, no hablaba, se hinchó, tenía deficiencia cardiaca. Estaban buscando inclusive en

2 el hospital una UCI [unidad de cuidado intensivo] pero no habian disponibles entonces la dejaron

Entrevista ahi, solo le pusieron fue una enfermera que ya estuviera pendiente ya toda la noche... iimagínese mujer, 2016 un médico también me dijo "la niña está muy grave pero confie en Dios"!

acá en la casa como a cuatro [nos dio], pero lo que le digo, la verdad es que no supimos que era,

3 si era el zika o el chikungunya... [¿dengue no era?] no porque el dolor, o sea era muy fuerte, 0 sea para un dengue no.

Entrevista

mujer, 2016

El chikungunya lo que yo tengo entendido, dicen que, o sea es muy parecido al dengue que es como dolor de cabeza, dolor de huesos, las articulaciones que duelen mucho y el broto por lo que

$4 \quad$ las plaquetas no bajan. No sé qué tenga que ver eso, es lo que yo tengo entendido, y el zika sé que

Entrevista por ahi escuché que es mero dolor de cabeza, mucho dolor de cabeza.

mujer, 2016 Yo si he escuchado que chikungunya y el zika dizque quedan secuelas y que eso vuelve a repetirse

5 dizque a los dos tres meses... quedan con las articulaciones doliendo, que ya no quedan igual como eran antes, que si van a alzar una olleta con agua ya les duele acá, o sea quedan las secuelas.

Pues el zika lo que uno oye, el zika da más miedo que los otros dos... porque ya en el caso de las mujeres de pronto estén en embarazo, es una enfermedad muy terrible para el bebé, entonces ese

Entrevista si me da más miedito porque ya esto ya con causar malformaciones y todo eso en caso de una mujer embarazada y a su bebé.

Mire el Zika es transmitido por el mismo zancudo que produce esa Aegypti. El Aegypti es el que

7 produce el dengue o que es el dengue clásico, ese mismo zancudo transmite el Zika y trasmite el Entrevista chikungunya.

Pues eso prácticamente da es por la, por el mosquito ese del del, iCómo es qué se llama? El caedes agyptus? (Cómo es? El zancudito ese... Ese es el transmisor del dengue y entonces ahi tienen precisamente, a veces hay carteleras donde, donde ellos mismos le expresan a la comunidad, por mujer, 2018 qué se da esa enfermedad.

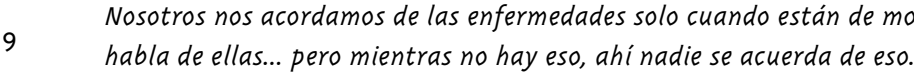


Entre hierbas, jugos y "remedios": caminos diferenciados frente a la experiencia de enfermedad

El itinerario terapéutico se compone de un durante y un después de la experiencia de enfermedad. Este itinerario incluye lo que las personas hacen, evitan, a donde acuden y el manejo o tratamiento que realizan. En el durante, entendido como el periodo en el que se advierte y enfrenta la enfermedad, confluyen elementos como el autocuidado, el manejo tradicional y popular de la enfermedad y la atención sanitaria.

En el autocuidado, cada persona define qué "tratamiento" o qué camino tomar a partir de sus recursos cercanos y experiencias previas (Tabla 2, citas 1-2). Los remedios caseros o populares y la automedicación surgieron como las primeras estrategias de contención de la enfermedad. Dentro de los múltiples remedios caseros destacan: (1) los jugos de frutas rojas; (2) consumo de cítricos; (3) infusiones de diferentes plantas; (4) los baños con plantas; y, (5) las dietas específicas (Tabla 2, citas 3-4). En la Tabla 3 se presentan los "remedios" considerados por los participantes. Muchos de estos remedios caseros funcionan tanto como medidas para evitar las enfermedades, así como una forma de afrontarlas. Estas medidas fueron recurrentes dando cuenta de la gran confianza que ponen en remedios, especialmente para controlar la "baja de las plaquetas" o "subir las defensas en el cuerpo".

\section{Tabla 2 - Citas sobre los itinerarios terapéuticos durante y después de la experiencia de enfermedad}

Texto
Eita
me di cuenta de que no me estaba muriendo, simplemente es un proceso que iba a llevar, y lo iba a
superar si seguía las recomendaciones que decian ahi. [...] Estaba en furor. Entonces que los síntomas
del Chikungunya, que los síntomas del Zika, como identificarlos, cada uno de los dos, cuales son
los tratamientos a llevar a cabo, en casos de que pase ciertas circunstancias asista al médico de
urgencias. Entonces uno llevaba eso muy puntual.
Con el zika y chikungunya duré varios días en mi casa porque también ya sabía cómo tratarlo,
tomando jugos de mora, acetaminofén es lo único que uno podia tomar, más no. Entonces uno para
qué va a perder tiempo [al médico] si sabe que lo que tiene que hacer. Cuidarse, no mojarse con agua
de la lluvia, no asolearse, tener como mucho reposo. Eso era lo que yo hacia.

La traté [chikungunya] con acetaminofén, aromáticas, calditos de pollo o carne y jugos de fruta y uva que la echo en una sartén sin nada de agua y la dejo sancochar un poquito... La uva negra chiquitica la dejo sancochar un poquito, la dejo enfriar y la licuo en la poquita agua que me quede bien el zumo de la mujer, 2016 uva y con eso le trato a los niños, le trato a mis hijos cuando se han enfermado a todos en la casa. cuando me empezaron a bajar mucho [las plaquetas, me daban] que caldos de pata de pollo y eso porque

4 las patas de pollo suben mucho eso, jugos de uva, la gelatina con lecherita, jugos de... hay un poco de jugos, recetas [...] la gente que come mucho higado y eso es de buenas defensas, pero yo no como eso. nosotros iqué hacemos?., pues buscar medicina alternativa, ya si vemos que el muchacho o la persona no evoluciona con lo que nosotros le estamos dando pues ya buscamos ino? de pronto el médico, buscamos nuestros ancestros, consultamos, con ellos y decimos: tenemos un problema asi y asi, iqué hacemos?

Por lo menos yo cuando tengo el niño enfermo, lo siento que me tiene fiebre yo corro. i[droguista]* qué
hago. y él le toma la temperatura y le da la medicina... es que eso es lo bueno, uno descansa en él... eso
es bueno de verdad que, que esté pendiente y la gente sepa cómo andamos en el barrio, porque es que
este barrio está muy grande.


Tabla 2 - Continuación

Tu llegas allá y te dicen tranquilo que el zika no lo mata es un virus y usted ardiendo en fiebre y ellos le dicen que tranquilito eso no es urgencia que eso es. Entonces uno para que tira para el hospital ya en el hospital llega uno cuando estas desmayado o sin signos vitales, asi es sencillo en el caso mío nosotros siempre utilizamos los baños de plantas naturales.

muchos colombianos no van al médico debidamente a eso, porque se ponen a sacar cuentas que van al médico y pagando transporte y lo que tienen que pagar porque me den esa, una miseria de pastillas

9 (refiriéndose al acetaminofén), siete mil, ocho mil, diez mil y aqui, aqui (en las droguerias) las hombre, 2018 pastillas valen mil quinientos, mil trecientos.

pero entonces ahorita si yo al dengue le cogi miedo, le cogi muchísimo miedo y como yo de todos modos

Io yo siempre cuando ellos se enferman sólo les doy acetaminofén hasta no saber qué es lo que le diga el médico porque hay por un error uno le dé y lo que hace es que lo enfermé más.

*farmacéutico.

Tabla 3 - "Remedios" caseros o populares para afrontar los síntomas del dengue, el chikungunya y el zika

Remedios caseros

Composición

Mora

a) Jugos de frutas rojas Agraz

Uva negra

Complementados con otros alimentos como lentejas y espinaca

Limón

b) Consumo de cítricos

Naranja

Mandarina

Jugos o en la dieta

Aromáticas de toronjilla

Aromáticas de flores

c) Infusiones de diferentes plantas

Aromáticas de manzanilla

Aromáticas de toronjil

Aromáticas de albahaca

"Agua de hierbas"

Cogollo de mango cocido

Avena en hojuelas

d) Baños con plantas

Sábila

Caléndula

Aguacate

Zanahoria

Pescado

Plátano

e) Dietas específicas

Purpura con leche y miel de abeja pura

Caldos de carne y pollo

Caldo de patas de pollo

En menor instancia se reconoce el uso de la medicina tradicional para el manejo de los primeros síntomas, referida como medicinas alternativas, naturales y de tradición familiar. Se identifican intervenciones terapéuticas ligadas a la movilidad geográfica y cultural que deriva en caminos híbridos de curación. En el caso particular de un entrevistado afro-colombiano se hizo más 
significativo el abordaje desde lo "natural", donde la cultura y la raza son base para la diferenciación. El manejo tradicional y popular de la enfermedad también involucra personas locales reconocidas como "especialistas". Figuras como el sobandero, experto en medicina natural en los barrios, y el espiritista, con conocimiento en "fármacos" y medicina naturista, son buscados para que les receten y les recomienden acciones. Acudir a las medicinas tradicionales o estas figuras apareció como una medida provisional antes de acudir a la atención sanitaria, a menos que el curso de la enfermedad terminara (Tabla 2, citas 2 y 5 ).

Finalmente, en la atención sanitaria se incluyen a las droguerías y a los servicios de salud. Las droguerías son reconocidas como el recurso de primera mano que posibilita el acceso a una atención "costo-efectiva”. Esa costo-efectividad se manifiesta en menor tiempo para la atención, cercanía y confianza (incluso afecto) con la persona tratante y menores costos directos e indirectos que acarrea la asistencia a los servicios sanitarios (transporte para llegar a los centros de atención, copagos y lucro cesante). Asimismo, las personas perciben que obtienen un rápido alivio al dolor y al malestar, aun cuando desconocen los métodos terapéuticos o "remedios" utilizados por el droguista y su manera de actuar para la resolución de sus dolencias. Dentro de este arsenal terapéutico las personas mencionaron el uso de acetaminofén, de vitaminas (tiamina) y de cócteles farmacéuticos, llamados matrimonios (Tabla 2, cita 6-9). Los servicios sanitarios en cambio son consultados en los casos de complicación de los síntomas, en el fracaso en las intervenciones anteriores o cuando la experiencia (en especial en casos de gravedad) los ha configurado como el recurso idóneo para el tratamiento (Tabla 2, cita 10).

En el después, definido como el proceso de apropiación y afrontamiento de los efectos de la enfermedad, se encontraron elementos como el dolor posterior, en el caso del chikungunya o el zika, y el miedo, particularmente a la muerte luego de la experiencia del dengue hemorrágico. Estos sentimientos dan cuenta tanto de las marcas de la enfermedad en el cuerpo como de sus significados en la cotidianidad, así como de los aprendizajes y temores en la redefinición y afrontamiento a partir de lo vivido. Este itinerario se conecta con las medidas preventivas que las personas realizan para evitar, anticiparse o afrontar un próximo episodio de enfermedad (Tabla 2, cita 11). A partir de estos elementos queda claro como los itinerarios terapéuticos se configuran y reconfiguran a partir de los aprendizajes que derivan las experiencias de enfermedad.

\section{Acetaminofén y AUTO-acetaminofén: encuentros $y$ desencuentros con el sistema sanitario}

Se identificaron dos itinerarios en el abordaje de estas enfermedades: uno, en sintonía con el sistema sanitario, y otro en resistencia a este. El primero, denominado en este trabajo "acetaminofén", corresponde a unas medidas que siguen las pautas médicas establecidas por el sistema sanitario para abordar las enfermedades en procura de no saturar los servicios de atención y prevenir complicaciones. El seguir esta ruta implica: controlar síntomas mediante analgésicos (específicamente acetaminofén) durante los primeros días y acercarse a las instituciones de salud después del tercer día para una valoración médica y toma de exámenes de laboratorio con el fin de definir diagnóstico y plan de tratamiento, a menos que un síntoma sea grave. Este itinerario estuvo presente especialmente en personas con experiencia propia o cercana de un episodio grave de dengue (Tabla 4, cita 1 y 2).

Si bien, esta es la pauta definida por el sistema sanitario y seguida por varias personas, otros de los participantes expresaron que asistir a los centros de salud cercanos se ha convertido en la última opción para tratar los síntomas que se presentan al tener alguna de estas enfermedades. Esto se debía a una expectativa fallida de la atención médica que prestan los servicios de salud generando "desconfianza" o "insatisfacción" debido a: primero, la demora en la prestación del servicio, lo cual lo descalifica en términos de su calidad y tiene un impacto negativo en la cotidianidad, ya sea porque los aleja de los deberes $y$, en muchos casos, les impide devengar recursos en su trabajo informal (Tabla 4, cita 3); segundo, los costos en términos de gastos económicos que representan los desplazamientos a los centros de atención; y, tercero, los medicamentos que se 
prescriben. Aquí es central la percepción ante el acetaminofén, pues es el medicamento que se receta para tratar cualquiera de las tres enfermedades (y otras), el cual es percibido como "malo" y "barato" (de bajo costo), lo que configura una percepción de precariedad en la atención ofrecida por el sistema sanitario que no les brinda acceso a los "mejores medicamentos" (Tabla 4, cita 4 y 5 ).

\section{Tabla 4 - Citas sobre encuentros y desencuentros con el sistema sanitario en la atención del dengue, el chikungunya y el zika}

\begin{tabular}{|c|c|c|}
\hline Cita & Texto & Fuente \\
\hline 1 & $\begin{array}{l}\text { Lo ideal es tomar un examen, irse al médico, tomarse un examen para que le dé, o sea } \\
\text { como descarte, iqué tiene? por ejemplo... Para mi eso, en el caso de mi familia eso es lo que } \\
\text { recomiendo. No soy asi como de auto medicarse... para mi los casos de dengue y eso, son } \\
\text { delicados... o sea, yo lo manejo en esa forma siempre con exámenes y como previniendo, pero } \\
\text { siempre con el médico. }\end{array}$ & $\begin{array}{l}\text { Entrevista } \\
\text { mujer, } 2016\end{array}$ \\
\hline 2 & $\begin{array}{l}\text { Pues el dolor de cabeza y el escalofrío. Yo siempre cuando los veo que están como malitos les } \\
\text { pregunto "iqué tiene? iqué le duele?" y ya si me dicen que le duele mucho la cabeza y que los } \\
\text { veo con escalofrio y que no me están comiendo entonces si más bien espero para llevarlos a } \\
\text { la clínica porque ahi si ya pues... o sea ya me da miedo que sea un dengue porque el dengue } \\
\text { creo que es asi que es un fiebre, dolor de cabeza, escalofrío, no comen y es durmiendo. }\end{array}$ & $\begin{array}{l}\text { Entrevista } \\
\text { mujer, } 2016\end{array}$ \\
\hline 3 & $\begin{array}{l}\text { Para el famoso zika ese, que hice yo, aqui abajo hay unos palitos de mango, aguacate, limón } \\
\text { y con eso yo hice baños y me bañaba pero el zika tiene una cuestión que debilita mucho las } \\
\text { partes coyunturales, si fue allá donde el man de la farmacia me auto medico porque no fui } \\
\text { al médico. Porque uno va allá al médico demoras dias sacando la cita y } 8 \text { días para que lo } \\
\text { atiendan entonces no hay razón de tu ir al hospital por una enfermedad de esas. }\end{array}$ & $\begin{array}{c}\text { Entrevista } \\
\text { hombre, } \\
2016\end{array}$ \\
\hline 4 & $\begin{array}{l}\text { En el caso del zika, me salió un broto, pero la realidad fue es que yo no fui al médico o sea no } \\
\text { fui en el momento. O sea, yo soy enemigo de ir al médico, porque si yo voy al médico me van } \\
\text { a dar un acetaminofén y toca esperar todo el dia. iA uno le da mamera ir al médico!, esa es la } \\
\text { realidad. Pero ya último me toco ir de verdad y iqué me dieron? un acetaminofén. 'Cuánto vale } \\
\text { un acetaminofén? en una droguería vale soo pesos y icuánto me vale ir al médico? } 4000 \text { pesos, } \\
\text { y la espera, y el tiempo, porque no dan más para eso, no dan más, isolo acetaminofén y que el } \\
\text { reposo y que tenga reposo y no dan más! }\end{array}$ & $\begin{array}{c}\text { Entrevista } \\
\text { hombre, } \\
2016\end{array}$ \\
\hline
\end{tabular}

Después de que mi hermano se llevó al médico e inclusive yendo con fiebre y pues con lo que presentaba sólo le dieron acetaminofén. Pues nosotros asumimos tomar acetaminofén y no ir al médico, entonces nosotros no fuimos al médico, ni mi mamá, ni yo... a mi pareja también le dio pero pues lo mismo... como lo único que se supone que pueden tomar es acetaminofén...

Entonces eso era lo que le decía "tome acetaminofén, no puede tomar nada más. Pues si quiere

Entrevista mujer, 2016 loratadina para el brotecito que le sale a uno y la rasquiña", que eso le ayudaba. Esas fueron las dos sugerencias que di por mi experiencia.

Es frente a estas insatisfacciones que se configura el segundo itinerario, denominado en este trabajo “AUTO-acetaminofén”. Con este concepto se hace referencia al conjunto de medidas para hacer frente a la enfermedad sin consultar el servicio sanitario, dado que el acetaminofén es percibido por las personas entrevistadas como "lo mismo de siempre" o "lo único que le mandan a uno".
Así, las personas prefieren tomar por su cuenta el acetaminofén que ir a un servicio sanitario, dado que este medicamento se consigue fácilmente, y sin necesidad de invertir mayor tiempo y dinero.

Estos dos itinerarios terapéuticos revelan el aprendizaje que produce la experiencia de la enfermedad y algunas relaciones que las personas tejen con el Sistema de Salud colombiano. 
Los desencuentros evidenciados revelan los cuestionamientos sobre el costo y el beneficio de buscar atención sanitaria. Para los participantes hacer uso del sistema de salud les da un conocimiento sobre las enfermedades, sobre su manejo y atención, que no necesariamente viene por una educación del profesional médico, sino que llega por la experiencia propia o cercana con estas. En este escenario, las droguerías y los farmacéuticos o droguistas adquieren un rol relevante en la vivencia cotidiana y resolución de los problemas de salud (Tabla 2, cita 6-9).

\section{Discusión}

En este trabajo se evidencian significados cotidianos e itinerarios terapéuticos frente al dengue, chikungunya y zika mediados por las experiencias de enfermedad y el encuentro o desencuentro con la atención que provee el sistema sanitario de Colombia, los cuales constituyen medios para el aprendizaje que definen la acción cotidiana frente a estas enfermedades.

Para abordar el conocimiento y los comportamientos poblacionales relacionados con las enfermedades se ha utilizado ampliamente la metodología conocimientos, actitudes y prácticas (CAP). Encuestas CAP han encontrado que el dengue no es masivamente reconocido como una enfermedad de origen infeccioso, sin embargo se advierte ampliamente que se contrae por la picadura de un mosquito, aunque los conocimientos sobre el vector y el mecanismo de transmisión del virus son limitados. Asimismo, muestran que la participación en actividades de control del mosquito es escasa, aunque se manifiestan actitudes favorables para el control (Cáceres-Manrique et al., 2009; Cooke et al., 2010; Diaz-Carrión et al., 2017; Hernández-Escolar; Consuegra-Mayor; Herazo-Beltrán, 2014; JaramilloRamírez; Buitrago Álvarez, 2017).

La metodología CAP está enmarcada en el lenguaje biomédico y, por tanto, no permite reconocer las nociones propias sobre la enfermedad, por lo que la no identificación del dengue como una enfermedad viral transmitida por mosquitos es interpretado como falta de conocimientos o ignorancia de las personas, la cual debe subsanarse mediante la educación, medidas de prevención de la enfermedad o promoción de estilos de vida saludables desde la perspectiva del personal sanitario.
En contraste con estos estudios, el abordaje de este trabajo permite adentrarse en la noción cotidiana de enfermedad y las formas en que la experiencia proporciona conocimientos sobre estas y cómo afrontarlas. En esta línea de trabajo, un estudio antropológico pionero realizado en Colombia (Villavicencio) encontró que el dengue es referido con un resfriado común que puede ser tratado fácilmente con medicamentos de venta libre y un poco de descanso. El empeoramiento de los síntomas es el que permite que las personas identifiquen que no están ante un resfriado sino que podría tratarse de un dengue (hemorrágico) (Suárez et al., 2009). Para abordar estas enfermedades, los autores identificaron un procedimiento habitual que comenzaba en casa con automedicación, pidiendo consejo a los vecinos, acudiendo a la farmacia, luego visitando a practicantes laicos y, como último recurso, visitando el centro de salud oficial o un médico autorizado.

En otro estudio realizado en Colombia (Neiva) a inicio de la década de los años 2000 también se identificaron dos modelos de percibir la enfermedad: uno tradicional "rompehuesos" y otro institucional "dengue", ambos referidos como gripas pero diferenciados por la mayor intensidad de los síntomas, la presencia de hemorragia, broto, vómito y posibilidad de morir en el "dengue". Las causas también eran diferenciadas, siendo desconocida en el caso del "rompehuesos", que se correspondería con el dengue clásico, mientras que para el dengue (hemorrágico) se identifican zancudos provenientes de aguas contaminadas como causa. Esta distinción en las causas y en los síntomas de las dos enfermedades se trasladaba a su manejo terapéutico, siendo el rompehuesos afrontado con recursos propios de la familia o la comunidad mientras que para el dengue se buscaba la atención médica institucional (Fajardo et al., 2001).

En Floridablanca también se identificaron dos tipos de dengue, siendo sus sintomatologías claramente distinguidas de un resfriado o gripa, y el dengue grave (con manifestaciones hemorrágicas) fue claramente relacionado con la posibilidad de morir. No obstante, en los tres municipios se encontraron itinerarios terapéuticos que se construyen alrededor del grado de severidad y la posibilidad de ser curado, ya sea por las mismas 
personas o por proveedores de salud, además, como lo plantea Suárez et al. (2009), estos itinerarios muestran que las personas han aprendido a convivir con el vector y las enfermedades, sin percibir que el mosquito o las enfermedades son las grandes amenazas que refiere el sector sanitario. Mosquito del que poco se sabe en términos biomédicos, como lo muestran también las encuestas CAP.

Como novedad en nuestros hallazgos, los itinerarios identificados no solamente están ligados a la severidad de los síntomas sino a la percepción de la atención proporcionada por los servicios de salud, la cual media la relación con el sistema sanitario en los contextos sociales de los participantes. De manera específica, el itinerario denominado AUTO-acetaminofén pone en evidencia cómo se tiende a enfrentar la enfermedad en condición de vulnerabilidad socioeconómica, en la que el abordaje del sistema sanitario no se percibe satisfactoria, debido -entre otras- a una construcción social negativa del acetaminofén, como un medicamento de bajo costo, de uso generalizado y fácil adquisición.

Si bien, se requiere profundizar en este hallazgo, se pone en evidencia una atención sanitaria en la que se gesta una comunicación carente de sentido para el paciente, en tanto no le es posible advertir las indicaciones y los beneficios de este medicamento para el tratamiento de las enfermedades estudiadas, en contraposición al logro de aprendizajes significativos en pro de una buena toma de decisiones en el cuidado de la salud y una relación de confianza con el sistema sanitario, que en el caso de Colombia paradójicamente cuenta como uno de sus grandes logros el aumento de cobertura, incluyendo la población en desventaja socioeconómica.

Este hallazgo debe interpretarse en el contexto del sistema sanitario colombiano, del que autores como Abadía-Barrero et al. (2008), Martínez, PinillaAlfonso y Abadía-Barrero (2018) y Hernández (2002) han descrito que con su reforma en la década de 1990 se aumentaron las barreras de acceso, lo cual derivó en servicios llenos de desigualdades frente a las necesidades de la población. En este sentido, el itinerario AUTO-acetaminofén puede entenderse como una respuesta a las indiferencias de un sistema sanitario percibido como desprestigiado por gran parte de la población.
En contraste con los servicios sanitarios, las droguerías (y el droguista) se configuraron como un escenario más consultado y valorado, constituyendo un elemento clave de los itinerarios. El reconocimiento de las farmacias comunitarias como los primeros puntos de atención sanitaria ha sido propuesto desde la farmacología social, postura que contrasta con el escaso reconocimiento que recibe la figura del farmaceuta dentro de las prestaciones biomédicas poblacionales (Armando; Vega; Uema, 2011). No obstante, estas pueden participar de un apropiado abordaje terapéutico cuando son incluidas como parte del proceso de atención de las poblaciones (Armando et al., 2005). En línea con los hallazgos, es pertinente reconocer la importancia que tienen las farmacias en el abordaje cotidiano de las enfermedades estudiadas, por lo que debería propenderse su integración con los servicios sanitarios, garantizando que el abordaje terapéutico empleado esté acorde a los algoritmos de atención vigentes en estos tres eventos.

Siguiendo a Augé (1996), los itinerarios develan tres sentidos de la enfermedad y su atención: lo geográfico, lo intelectual/cognitivo y lo histórico, situación que nos permite entender los complejos procesos sociales de la salud. Al igual que otros trabajos sobre itinerarios terapéuticos (Pinho; Pereira, 2012; Nabão; Maruyama, 2009), este estudio muestra esta configuración de los itinerarios. Todas estas instancias proveen aprendizajes que definen itinerarios posteriores en intersección de procesos políticos, económicos, sociales, interacciones cotidianas y biografías.

Por otro lado, el reconocimiento e identificación de las enfermedades "nuevas", chikungunya y zika, se encontró mediado por la presencia de casos en el territorio. Ante la aparente ausencia de casos, estos eventos son "olvidados" o entendidos como otras formas de llamar las enfermedades ya conocidas, en este caso, el dengue. Esta manera de "olvidar" y de "apropiarse" de términos nuevos, es un fenómeno colectivo evidenciado en otras zonas del país con alta presencia de dengue (Pacheco; Martínez, 2013). Al no percibirse una clara diferenciación entre estos eventos y el dengue, los dos itinerarios terapéuticos evidenciados fueron planteados indistintamente ante las tres enfermedades. 
Así, la construcción social del dengue, chikungunya y zika está atravesada por una tensión fundamental entre el reconocimiento y el olvido. Esta tensión obliga a analizar la forma en que estas enfermedades se inscriben y se transforman en las racionalidades, creencias e intereses tanto del personal de salud y tomadores de decisión como de las personas de un territorio. En el contexto de la mayor y menor presencia temporal de casos, "reconocimiento y olvido", se resalta el papel de los medios masivos y alternativos de comunicación tales como la internet y el "voz a voz" como fuentes importantes de conocimiento en salud. Estos medios permiten la apropiación de un conocimiento que puede estar o no en sintonía del conocimiento biomédico, pero es valorado socialmente y con base en este se toman decisiones importantes, como acercarse o no a los servicios de atención, por lo cual debe tomarse seriamente el papel de estos medios en la agencia de la salud que tienen las personas. En este sentido, resulta clave garantizar que cada contacto con el sistema sanitario represente una fuente de aprendizaje significativo para el cuidado de la salud de quienes acuden a los servicios sanitarios, teniendo presente que sus percepciones y opiniones son fuente de conocimiento para otras. Este aprendizaje debe basarse en el diálogo de saberes entre el personal sanitario y las personas de la comunidad, no en la imposición vertical de conocimiento biomédico.

\section{Consideraciones finales}

Este artículo deja planteadas reflexiones sobre el papel de las entidades sanitarias, las creencias de los individuos sobre las enfermedades, y los múltiples procesos terapéuticos para afrontarlas.

Los hallazgos sobre la construcción social del dengue, chikungunya y zika mediada por la tensión reconocimiento y olvido, instan a revisar las maneras en que estas enfermedades son objeto de políticas y acciones públicas, en las que se espera la participación de la comunidad, ya sea para cortar el ciclo de reproducción del mosquito al interior de sus viviendas o para hacer un uso racional de los servicios de atención. Estas políticas y acciones tienen el reto de enfrentar el "olvido" que trae la cotidianidad, por lo que es fundamental no limitarse a estrategias y abordajes que ignoran las maneras en que las enfermedades son vividas, sentidas y afrontadas.

De otro lado, los itinerarios terapéuticos identificados destacan el rol activo de las personas en la toma de decisiones ante un abanico de métodos terapéuticos que encuentran en su vida diaria. En un panorama de pluralismo médico, claramente hay variadas razones para tomar por un camino terapéutico u otro, pero debe considerarse que las personas deciden de acuerdo con una noción propia sobre el costo y la efectividad de opciones a las que puede acudir, la cual van construyendo a través de experiencias propias y cercanas de enfermedad, atención y resultados obtenidos.

En consonancia con estos argumentos, se propone profundizar en: (1) la agencia que tienen los individuos para la resolución de sus malestares de salud y el papel que cumplen los medios masivos y alternativos de comunicación en la misma; (2) el rol que tienen los profesionales de salud asistenciales como educadores para la salud de las personas y los colectivos; (3) las relaciones que construyen las personas con los servicios sanitarios y el sistema de salud y cómo estas pueden favorecer o no la salud, tanto de las personas como de las poblacionales.

\section{Referencias}

ABADÍA-BARRERO, C.; OVIEDO-MANRIQUE, D.

Bureaucratic Itineraries in Colombia.

A theoretical and methodological tool to assess managed-care health care systems. Social Science \& Medicine, Oxford, v. 68, n. 6, p. 1153-116o, 2009.

ABADÍA-BARRERO, C. et al. Perspectivas intersituadas al capitalismo en salud: desde Colombia y sobre Colombia. Palimpsestus, Bogotá, DC, v. 6, p. 163-176, 2008.

ALVES, P. C. B.; SOUZA, I. M. Escolha e avaliação de tratamento para problemas de saúde: considerações sobre o itinerário terapêutico. In: RABELO, M.; ALVES, P.; SOUZA, I. Experiência de doença e narrativa. Rio de Janeiro: Ed. Fiocruz, 1999. p. 125-138. 
ARAUZ, M. J. et al. Developing a social autopsy tool for dengue mortality: a pilot study. PLOS $O N E$, São Francisco, v. 10, n. 2, p. 1-17, 2015.

ARMANDO, P.; VEGA, E.; UEMA, S. Imagen profesional de farmacias comunitarias: causas y estrategias de mejora aplicando técnicas de investigación cualitativa. Revista de Salud Pública, Bogotá, DC v. 13, n. 2, p. 274-287, 2011.

ARMANDO, P. et al. Seguimiento farmacoterapéutico de pacientes en farmacias comunitarias. Atención Primaria, Madri, v. 36, n. 3, p. 121-175, 2005.

AUGÉ, M. Conclusión. In: AUGÉ, M. El sentido de los otros. Actualidad de la antropología. Barcelona: Paidós, 1996. p. 109-119.

CABRAL, A. L. et al. Itinerários terapêuticos: o estado da arte da produção científica no Brasil. Ciência \& Saúde Coletiva, Rio de Janeiro, v. 16, n. 11, p. 4433-4442, 2011.

CÁCERES-MANRIQUE, F. M. et al. Conocimientos, actitudes y prácticas sobre dengue en dos barrios de Bucaramanga, Colombia. Revista de Salud Pública, Bogotá, DC, v. 11, n. 1, p. 27-38, 2009. CASTRILLÓN, J. C.; CASTAÑO, J.C.; URCUQUI, S. Dengue en Colombia: diez años de evolución. Revista Chilena de Infectología, Chile, v. 32, n. 2, p. 142-149, 2005 .

COOKE, A. et al. Conocimientos, actitudes y prácticas sobre dengue en dos barrios del corregimiento de Pocrí, Distrito de Aguadulce, Provincia de Coclé. Panamá. Revista MédicoCientífica, Panamá, v. 23, n. 2, p. 12-23, 2010. DÍAZ-CARRIÓN, G. R. et al. Conocimientos y prácticas sobre prevención de dengue en un Distrito de Lambayeque, Perú, 2015. Revista del Cuerpo Médico del HNAAA, Perú, v. 10, n. 3, p.121-125, 2017.

FAJARDO, P. et al. Nociones populares sobre "dengue" y “rompehuesos", dos modelos de la enfermedad en Colombia. Revista Panamericana de Salud Pública, Washington, DC, v. 10, n. 3, p. 161-169, 2001.
GUHA-SAPIR, D.; SCHIMMER, B. Dengue fever: new paradigms for a changing epidemiology. Emerging Themes in Epidemiology, Londres, v. 2, 2 Mar. 2005.

HERNÁNDEZ, M. Reforma sanitaria, equidad y derecho a la salud en Colombia. Cadernos de Saúde Pública, Rio de Janeiro, v. 18, n. 4, p. 991-1001, 2002.

HERNÁNDEZ-ESCOLAR, J.; CONSUEGRA-MAYOR, C.; HERAZO-BELTRÁN, Y. Conocimientos, actitudes y prácticas sobre Dengue en un barrio de la ciudad de Cartagena de Indias. Revista de Salud Pública, Bogotá, DC, v. 16, n. 2, p. 281-292, 2014.

JARAMILLO-RAMÍREZ, G. I.; BUITRAGO ÁLVAREZ, L. S. Knowledge, attitudes and practices regarding Dengue, Chikungunya, and Zika and their vector Aedes Aegypti in Villavicencio, Colombia. The Open Public Health Journal, Xarja, n. 10, p. 8o-89, 2017.

JARAMILLO-TOBÓN, C. Infecciones por Virus ZIKA en Colombia - 2015. Revista Medicina UCSG, Guaiaquil, v. 19, n. 2, p. 125-133, 2015.

MARTÍNEZ-PARRA, A.; PINILLA-ALFONSO, M. Y.; ABADÍA-BARRERO, C. Sociocultural dynamics that influence Chagas disease health care in Colombia. Social Science \& Medicine, Oxford, n. 215, p. 142-150, 2018.

MENÉNDEZ, E. Modelos de atención de los padecimientos: de exclusiones teóricas y articulaciones prácticas. Ciência \& Saúde Coletiva, Rio de Janeiro, v. 8, n. 1, p. 185-207, 2003.

MILES, M.; HUBERMAN, A. M. Data management and analysis methods. In: DENZIN, N.; LINCOLN, Y. (Ed.). Handbook of qualitative research. Londres: Sage, 200o. p. 769-802.

NABÃO, F.; MARUYAMA, S. A. A experiência da enfermidade e o itinerário terapêutico vivenciado por uma pessoa com infarto. Revista Eletrônica de Enfermagem, Goiânia, v. 11, n. 1, p. 101-109, 2009.

PACHECO, A.; MARTÍNEZ, A. Participación comunitaria y Aedes aegypti en La Dorada, Caldas: políticas, salud pública y concepciones desde la comunidad. In: Abadía et al. Salud, normalización y 
capitalismo en Colombia. Bogotá, DC: Universidad Nacional de Colombia, 2013. p. 51-77.

PADILLA, J. C. et al. Epidemiología de las principales enfermedades transmitidas por vectores en Colombia, 1990-2016. Biomédica, Bogotá, DC, v. 37, p. 27-40, 2017. Suplemento 2.

PINHO, P.; PEREIRA, P. Itinerários terapêuticos: trajetórias entrecruzadas na busca por cuidados. Interface, Botucatu, v. 16, n. 41, p. 435-447, 2012.

SALDAÑA, J. The coding manual for qualitative researchers. 2. ed. Londres: Sage, 2013.

SUÁREZ, R.; GONZÁLEZ, C.; VIATELA, J. M. Dengue, políticas públicas y realidad sociocultural: una aproximación al caso colombiano. Revista Colombiana de Antropología, Bogotá, DC, v. 40, p. 185-212, 2004.

SUÁREZ, R. et al. Is what I have just a cold or is it dengue? Addressing the gap between the politics of dengue control and daily life in VillavicencioColombia. Social Science \& Medicine, Amsterdã, v. 61, n. 2, p. 495-502, 2005.

SUÁREZ, R. et al. An ecosystem perspective in the socio-cultural evaluation of dengue in two Colombian towns. Cadernos de Saúde Pública, Rio de Janeiro, v. 25, p. 104-114, 2009. Suplemento 1.

WHO - WORLD HEALTH ORGANIZATION. Global strategy for Dengue prevention and control 2012-2020. Paris, 2012.

\section{Agradecimientos}

Los autores agradecen la financiación otorgada por la Universidad Autónoma de Bucaramanga y la Universidad del Rosario para realizar la investigación.

\section{Contribución de los autores}

Hormiga y Cortés diseñaron la investigación y lideraron las fases de recolección de información, análisis y elaboración del manuscrito. Becerra, Ariza, Garzón y Cadena participaron en la recolección, análisis y elaboración del manuscrito.

Recibido: 07/02/2019

Aprobado: 03/03/2020 